\title{
Combined markers for predicting cognitive deficit in patients with Alzheimer's disease
}

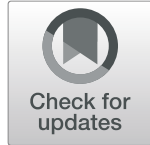

Dalia Farouk Hussen ${ }^{1 *}$ (D, Ayat Allah Farouk Hussein², Mahmoud Abdel Moety Monzer ${ }^{3}$ and Saida Ali Hammad ${ }^{1}$

\begin{abstract}
Background: Alzheimer's disease (AD) is the most widely recognized type of dementia. It is associated with cell cycle abnormalities including genomic instability and increased micronuclei (MNi) which usually evolve many years before the appearance of the clinical manifestations. Digital electroencephalogram (EEG) has a role in perceiving brain changes in dementia and in early detection of cognitive decline. This study aimed to assess the competency of using neurophysiological markers including absolute power of alpha waves and a cytogenetic marker which comprises scoring of MNi as a step toward early and preclinical diagnosis of AD. The study was conducted on 27 subjects; they were 15 patients diagnosed as sporadic AD and a group of 12 age and sex-matched controls. All subjects were subjected to Mini-Mental State Examination (MMSE), conventional EEG, digital EEG, and cytokinesisblock micronucleus assay (CBMN) in peripheral blood lymphocytes.

Results: Conventional EEG showed a normal background activity with no abnormal epileptogenic discharges in both groups. Digital EEG showed significant reduction of the absolute power of alpha waves for AD patients as compared to the control group $(P<0.0001)$. Score of MNi showed statistical significant difference between the two groups $(P<0.0001)$. By linking scores of both cognitive state using MMSE and MNi among the group of patients, a significant negative correlation was detected $(r=-0.6066)$. The correlations between cognitive state and the absolute power of alpha wave among the patients revealed a positive correlation $(r=0.2235)$.

Conclusions: The combination of both cytogenetic and neurophysiological markers can be beneficial for early detection of cognitive decline and may lead to preclinical identification of individuals at increased risk for AD, where at this stage treatment is constructive. The negative correlation between the scores of MNi and MMSE is suggestive for the impact of genomic instability on the cognitive state.

Keywords: Alzheimer's disease (AD), Mild cognitive decline, Mini-Mental State Examination (MMSE), Cytokinesisblock micronucleus assay (CBMN), Micronuclei (MNi), Electroencephalogram (EEG), Neurophysiological marker, Cell cycle
\end{abstract}

\section{Background}

Dementia is a regression in the cognitive function which usually appears as a major affection of intellectual abilities to the extent that interferes with social or occupational functions beyond what might be expected from normal aging [1].

\footnotetext{
*Correspondence: daliafarouk55@gmail.com

'Department of Human Cytogenetics, Human Genetics and Genome Research Division, The National Research Centre, 33 El Buhouth Street, El-Dokki, Cairo 12622, Egypt

Full list of author information is available at the end of the article
}

Alzheimer's disease (AD) is the most common form of dementia to date and the most common neurodegenerative disorder [2]. Nowadays, 34 million people are suffering from $\mathrm{AD}$ worldwide, and by 2050 this value is expected to increase to 115 million [3]. In low- and middle-income countries, $\mathrm{AD}$ is suspected to increase by a considerable higher level [4].

Alzheimer's disease is a slowly progressive brain disease that includes preclinical and clinical stages, clinical stage starts with mild cognitive decline that does not significantly interfere with the patients daily activities, then

\section{Springer Open}

(๑) The Author(s). 2021 Open Access This article is licensed under a Creative Commons Attribution 4.0 International License, which permits use, sharing, adaptation, distribution and reproduction in any medium or format, as long as you give appropriate credit to the original author(s) and the source, provide a link to the Creative Commons licence, and indicate if changes were made. The images or other third party material in this article are included in the article's Creative Commons licence, unless indicated otherwise in a credit line to the material. If material is not included in the article's Creative Commons licence and your intended use is not permitted by statutory regulation or exceeds the permitted use, you will need to obtain permission directly from the copyright holder. To view a copy of this licence, visit http://creativecommons.org/licenses/by/4.0/. 
the mild cognitive decline usually progresses to dementia as patients at this stage are characterized by obvious memory and behavioral symptoms that impair a person's ability to function in daily life. The preclinical stage usually starts 20 years or more before mild cognitive decline occurs. Patients at the preclinical stage has no symptoms while there are usually measurable changes in the brain, and biomarkers in the cerebrospinal fluid as well as in blood that indicate the earliest signs of the disease [2].

Detection of biomarkers for early diagnosis and screening is highly beneficial, where at this stage treatment can be constructive [5].

Genomic instability is the earliest neuropathological event detected at the preclinical phase of the disease [6-8].

Studies in peripheral lymphocytes of patients with Alzheimer's disease (AD), revealed genomic instability in the form of increased micronuclei (MNi) formation compared to age and sex healthy controls. Micronucleus usually originates from a whole chromosome or acentric chromosome that is retarded in the cell cycle during anaphase and remains outside the daughter nuclei [9]. It usually arises as a result of malsegregation due to mitotic malfunctioning. Thus, it can be used as a biomarker to investigate and follow genomic instability and deoxyribonucleic acid (DNA) damage. Significant change in the $\mathrm{MNi}$ frequency reflects reduced regenerative ability and this may prove its usefulness as a potential future diagnostic marker to identify individuals of increased risk for $\mathrm{AD}$ [10] as this DNA damage may be associated with cognitive decline [11].

Although increased MNi formation as a cytogenetic marker can be an indicator for cognitive affection, this should be augmented simultaneously with functional neurophysiological markers using electroencephalogram (EEG) $[12,13]$.

EEG is a noninvasive functional neuroimaging method that can be used for early detection of cognitive decline. Moreover, it is widely available and faster than other imaging techniques [14].

This study is an attempt to detect the frequency of micronuclei formation within patients of $\mathrm{AD}$ and to test the correlation between micronuclei frequency, EEG changes, and the cognitive state. As genome integrity loss could be associated with an increased risk for neurodegeneration, coalescing genetic markers including micronuclei frequency with neurophysiological marker in the form of absolute power of alpha wave may be successful for detecting early cognitive decline.

\section{Methods}

\section{Patients}

This study was conducted on 27 subjects; they included 15 patients diagnosed clinically as sporadic AD. They comprised 10 females (66.7\%) and 5 males (33.3\%), their ages ranged from 66-71 years with mean age of 67.73 years. All selected patients were fulfilling specific inclusion criteria; they were above 65 years of age and confined between mild and moderate stage of $\mathrm{AD}$ according to the Diagnostic and Statistical Manual of Mental Disorders, 5th ed. (DSM V) [15]. All patients were on cholinesterase inhibitors.

We have excluded patients with some criteria as age below 60 years, smokers, diabetics, history of medical or other neuropsychiatric disorders which may be the cause of his/her cognitive decline. Patients with motor disability and patients with a disturbed level of consciousness or late stages of $\mathrm{AD}$ have been also excluded. A group of 12 age and sex-matched healthy volunteers has been enrolled in the study.

All patients and controls were subjected to the following:

\section{Clinical studies}

History taking and thorough clinical examination including neuropsychological examination and cognitive screening were performed. Screening for cognitive impairment was performed using the Mini-Mental State Examination (MMSE) test, which is a brief 30-point questionnaire [16, 17]. It measures various functions including memory, orientation, and arithmetic. A score $\geq 25$ points is effectively normal. Scores below 25 points can indicate mild (21-24 points), moderate (10-20 points), or severe ( $\leq 9$ points) affection.

\section{Imaging}

All cases underwent magnetic resonance imaging (MRI) to exclude other causes of dementia.

\section{Conventional encephalogram (EEG) and digital EEG}

The EEG was recorded using standardized techniques with electrode locations based on the international 1020 system. A standard 21-channel cup was used; electrode impedance was kept lower than 5 kiloohms $(\mathrm{k} \Omega)$. Band pass filter (0.53-35 Hz) (EEG-9200k, Nihon Kohden Corporation, Tokyo, Japan).

EEG results were visually scored, background activity for detection of the alpha rhythm then detection of epileptic discharges either focal or generalized.

\section{Spectral analysis}

Artifact free recordings were selected and then ten epochs of $10 \mathrm{~s}$ each were analyzed by applying Fast Fourier Transfer-Spectral EEG, and the mean absolute power spectrum was calculated for the frequencies of delta $(1-4 \mathrm{c} / \mathrm{s})$, theta $(5-7 \mathrm{c} / \mathrm{s})$, alpha $(8-12 \mathrm{c} / \mathrm{s})$, and beta $>13 \mathrm{c} / \mathrm{s}$ waves.

Normal reference patterns for EEG were established from the evaluation of cerebral function in healthy volunteers. 


\section{Cytogenetic studies}

A venous blood sample (3-3.5 ml) was taken from each patient and healthy volunteer under aseptic conditions into a sterile heparin-coated vacutainer. Culture tubes were prepared as follows: each $100 \mathrm{ml}$ bottle of RPMI 1640 was added to $25 \mathrm{ml}$ fetal bovine serum, $4 \mathrm{ml} \mathrm{L-glu-}$ tamine, $1.5 \mathrm{ml}$ penicillin/streptomycin solution, and 5 $\mathrm{ml}$ of phytohemagglutinine. They were mixed well and distributed in sterile falcon's flat tipped $5 \mathrm{ml}$ tubes, and then $0.4 \mathrm{ml}$ blood was added for each culture tube. For each individual in the study, 2 culture tubes were set up under laminar air flow to avoid any contamination.

Cytokinesis-block micronucleus assay (CBMN) in peripheral blood lymphocytes was done to detect chromosomal malsegregation. After initiation of culture at $37^{\circ} \mathrm{C}$ by $44 \mathrm{~h}(\mathrm{~h})$, blocking of cytokinesis with cytochalasin-B (Cytochalasin B from Drechslera dematioidea, Sigma Aldrich (now Merck)) have been done in which scoring is selectively directed to binucleated cells $(\mathrm{BN})$, as these are cells that can present $\mathrm{MNi}$ [18], then the culture was completed for another 24-28 $\mathrm{h}$ before harvest and Giemsa staining. Five hundred $\mathrm{BN}$ were studied and multiplied by two for each case for scoring of $\mathrm{MNi}$. BN cells with $\mathrm{MNi}$ were photographed using computer supported image analyzer (computer-assisted camera system; Applied Imaging, San Jose, CA, USA). Scoring of $\mathrm{MNi}$ in $\mathrm{BN}$ cells prevents confusing effects caused by altered cell division kinetics [9].

\section{Statistical analysis}

Test results were expressed as mean \pm SD. Data were evaluated and compared using non-parametric MannWhitney test using GraphPad Prism software (version 6.01), GraphPad software, San Diego, CA, USA.

\section{Results}

The mean score of MMSE was $18.07 \pm 4.026$ among the $\mathrm{AD}$ patients, while for controls the mean score was $28.73 \pm 1.443$. MMSE score was done for controls to exclude being in early undiagnosed stage of mild cognitive decline and to allow validation of their both EEG results and their blood samples as control samples. Conventional EEG showed a normal background activity in both the controls and the group of patients, as no abnormal epileptogenic discharges have been detected. Digital EEG showed lower mean absolute power of alpha waves among the patients $(6.207 \pm 0.3011)$ (Fig. 1) compared to the controls $(17.21 \pm 0.5567)$ (Fig. 2). Statistical analysis revealed a highly significant difference between the two group $(\mathrm{P}<0.0001)$ (Table 1$)$. Mean absolute power of other frequencies was within normal range for both patients and control groups.

For cytokinesis-block micronucleus assay (CBMN), mean score for patients was $10.13 \pm 3.420$ (Fig. 3), while

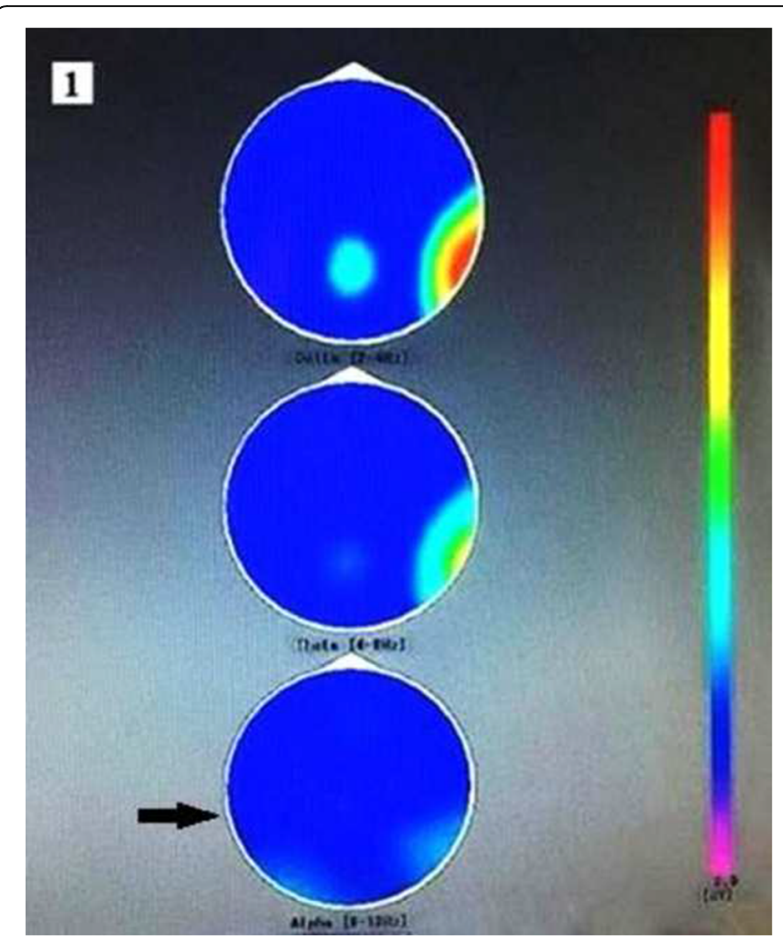

Fig. 1 Digital EEG; showing low power alpha waves for an AD patient, arrow pointed to the reduced alpha wave

for controls was $3.167 \pm 2.329$ (Fig. 4). Statistical analysis of data using non-parametric Mann-Whitney test revealed a highly significant difference between the two groups $(\mathrm{P}<0.0001)$. By linking scores of both cognitive screening using MMSE and MNi using CBMN among the group of patients, a significant negative correlation was detected between the two scores $(r=-0.6066)$ (Fig. 5). The correlations between cognitive state and the absolute power of alpha wave among the patients revealed a positive correlation $(r=0.2235)$ (Fig. 6), whereas the correlation between the absolute power of alpha wave and the MNi score was non-significant ( $\mathrm{r}=$ $-0.06844)$.

\section{Discussion}

Alzheimer's disease is a slowly progressive cerebral disease that includes preclinical and clinical stages. The preclinical stage usually starts many years before mild cognitive decline occurs. Patients at the preclinical stage are virtually asymptomatic while there are usually measurable changes in the brain, and biomarkers in the cerebrospinal fluid as well as in blood that indicate the earliest signs of the disease [2].

Although biomarkers in the cerebrospinal fluid are considered more specific, they are only detected through invasive lumbar puncture which has various complications [19]. Blood and neurophysiological imaging could 


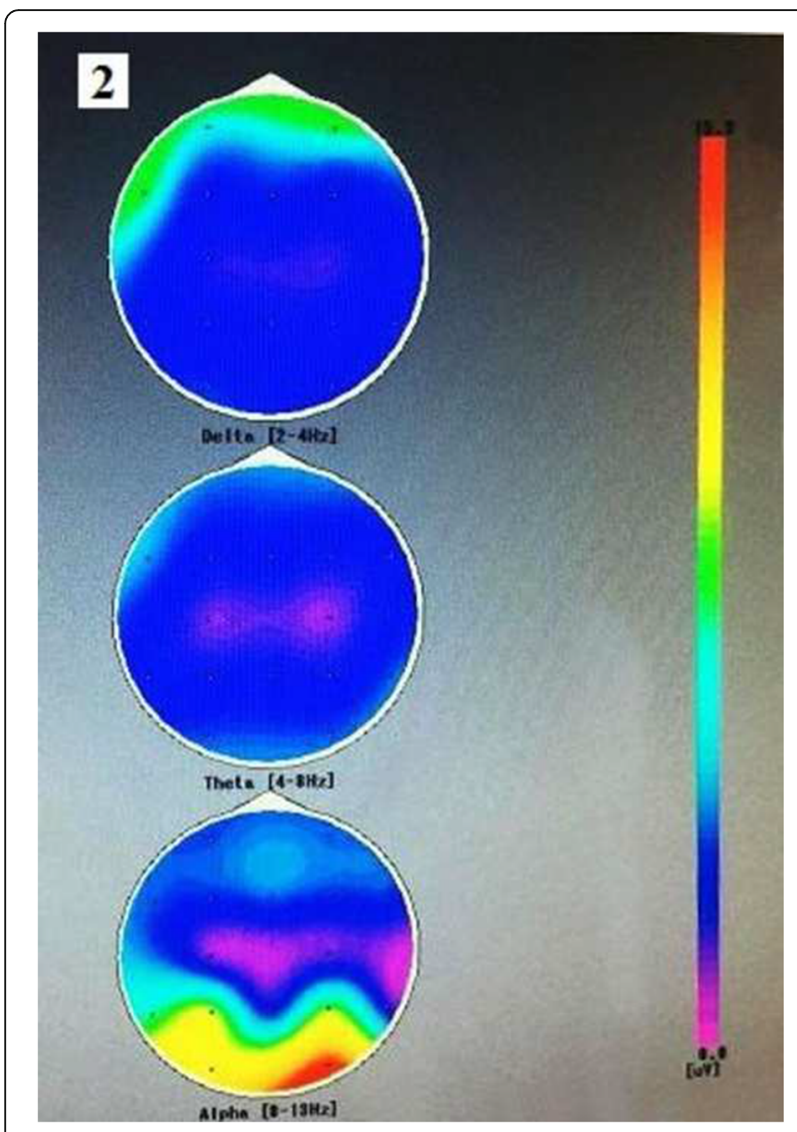

Fig. 2 Digital EEG; showing normal alpha waves for a normal control subject

serve as sources for detecting biomarkers through noninvasive methods and at a lower cost.

In the present study, an attempt has been made aiming to evaluate the efficacy of combined noninvasive markers including the score of $\mathrm{MNi}$ in $\mathrm{BN}$ lymphocytes in peripheral blood as well as digital EEG parameters for early diagnosis of $\mathrm{AD}$.

All patients and controls were subjected to history taking, thorough clinical examination including neuropsychological examination, and MRI to exclude other causes of dementia. Screening for cognitive function has been done using MMSE. The mean score for MMSE was $18.07 \pm 4.026$ among the $\mathrm{AD}$ patients, while for

Table 1 Showing significant statistical difference between parameters of patients and controls

\begin{tabular}{llll}
\hline Variable & Controls & Patients & P value \\
\hline Number of subjects & 12 & 15 & ---- \\
MMSE & $28.73 \pm 1.443$ & $18.07 \pm 4.026$ & --- \\
$\begin{array}{l}\text { Mean value of alpha } \\
\text { wave power }\end{array}$ & $17.21 \pm 0.5567$ & $6.207 \pm 0.3011$ & $P<0.0001$ \\
Mean score of $\mathbf{M N i}$ & $3.167 \pm 2.329$ & $10.13 \pm 3.420$ & $P<0.0001$
\end{tabular}

MNi micronuclei, MMSE Mini-Mental State Examination

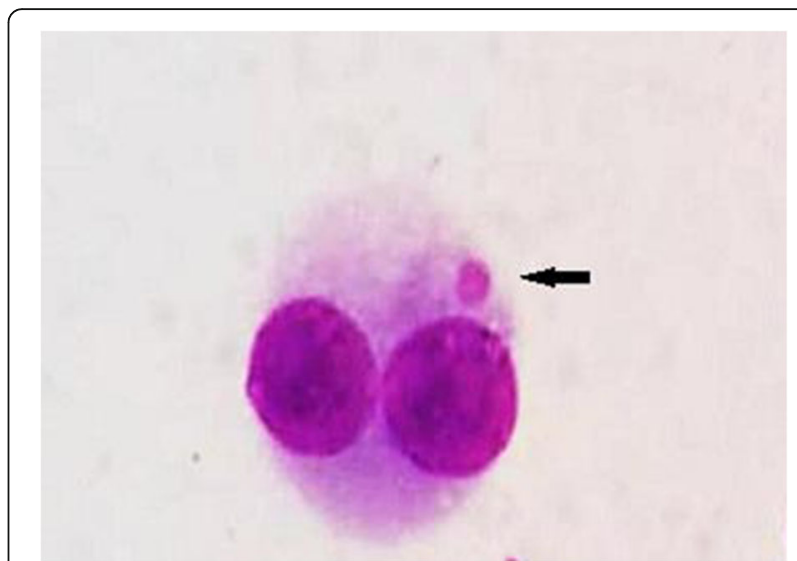

Fig. 3 Cytokinesis-block micronucleus assay (CBMN); showing binucleated micronucleated (BNMN) lymphocyte of an AD patient, arrow pointed to the micronucleus

controls the mean score was $28.73 \pm 1.443$. MMSE score was done for controls to exclude being in early undiagnosed stage of mild cognitive decline, to allow validation of both their EEG results and blood samples as control samples.

The use of EEG has grown prevalent for its capabilities in evaluating cerebral degenerative changes in dementia. Several studies have been directed to deal with EEG changes associated with dementia and to identify its degree of severity [20]. Furthermore, many studies praise

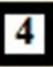

Fig. 4 Cytokinesis-block micronucleus assay (CBMN); showing lymphocytes of a normal control subject; they are binucleated cells without micronuclei 


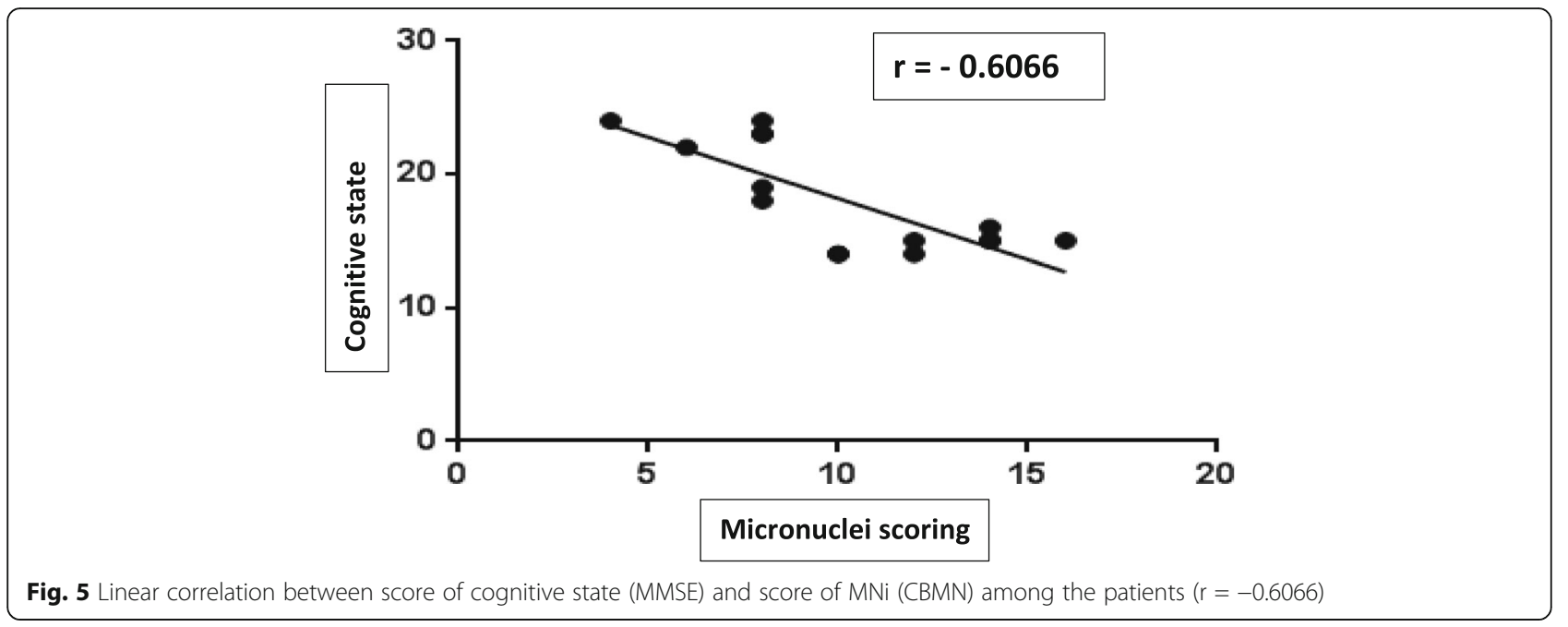

the role of EEG as a marker in the early detection of AD $[21,22]$.

By using conventional EEG in our study, we found normal background activity with no abnormal epileptogenic discharges in both the patient and the control groups. However, digital EEG revealed lower mean absolute power of alpha waves among the patients $(6.207 \pm 0.3011)$ compared to the controls $(17.21 \pm 0.5567)$. Statistical analysis revealed a highly significant difference between the two groups $(\mathrm{P}<0.0001)$. Mean absolute power of other frequencies was within normal ranges for both patient and control groups. Our study was in agreement with the research study of De Waal et al. [23] which revealed more EEG abnormalities in AD patients compared to the controls ( $\mathrm{p}<0.001)$. Furthermore, Fauzan and Amran [24] in their study reported a significant reduction in rhythmic alpha frequencies among patients with mild cognitive impairment compared to the controls.
Moreover, Snyder et al. [13] stated that EEG may have an important role in detecting and classifying dementia regarding its significant influence in terms of rhythm activity that appears in patients with dementia. Micanovic and Pal [25] as well as Raymundo et al. [26] emphasized that visual analysis EEG can contribute in diagnosis of $\mathrm{AD}$ as it usually reveal power spectrum shifts from highfrequency components (alpha, beta, and gamma) toward low-frequency components (delta and theta).

In the current study, the correlations between cognitive state and the absolute power of alpha wave among the group of patients revealed a positive correlation $(\mathrm{r}=$ 0.2235). Although this correlation is considered relatively weak, we suggest that reduced alpha wave power could support the diagnosis when combined with another parameter.

We hypothesized in our study that depending on a single marker reduces the probability of reaching

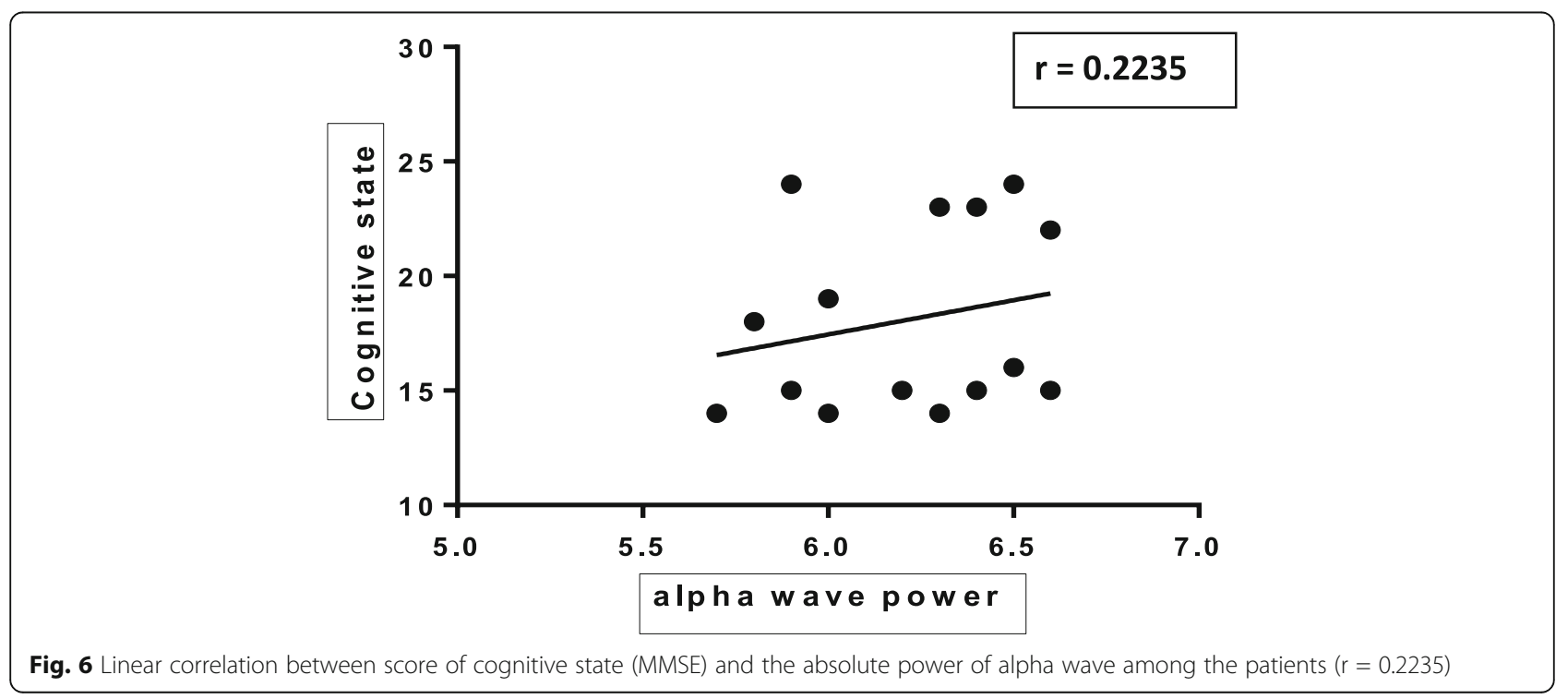


appropriate diagnosis. So, we combined the neurophysiological markers with a genetic marker in a trial to reach reliable findings.

Bajic et al. [8] clarified that there is an increasing interest in the evaluation of DNA damage markers in individuals liable to develop AD. These biomarkers may identify individuals at early stages of neurodegeneration. This would be useful to allow for appropriate interventions prior to progression of the disease. Moreover, Zivković et al. [7] declared that genetic instability occurs a number of years prior to clinical diagnosis.

Additionally, Andreassi et al. [27] emphasized that scoring of the $\mathrm{MNi}$ is the most prevalent biomarker for assessing DNA damage in peripheral blood lymphocytes.

Regarding our study, the mean score of $\mathrm{MNi}$ among the patients was $10.13 \pm 3.420$, whereas among controls was $3.167 \pm 2.329$. Statistical analysis of data revealed a highly significant difference between the two groups ( $P$ $<0.0001)$. These results are consistent to the study done by Trippi et al. [28] which revealed an increase in the score of $\mathrm{MNi}$ in $\mathrm{AD}$ patients $(\mathrm{P}<0.05)$, where the mean scores of the patient and control groups were $20.8 \pm 9.2$ and $9.0 \pm 6.8$, respectively. Additionally, Petrozzi et al. [29] revealed a compatible results to our study as they found a statistical significant difference between patients' mean score of $\mathrm{MNi}$ (18.26) versus that of controls (8.56) $(\mathrm{P}<0.05)$.

Our results are in contrast to the study done by Lee et al. [11] which showed a non-significant difference in the score of $\mathrm{MNi}$ among South Australian AD patients compared to controls $(\mathrm{P}<0.18)$. They attributed these results to the environmental diversity between the study population in their research and the previous researches regarding dietary and lifestyle factors [30]. Additionally, the level of $\mathrm{MNi}$ in the controls may have already exceeded the threshold of spotting any significant differences compared to AD patients [11].

By linking scores of both cognitive screening using MMSE and MNi among the patients, our study found a significant negative correlation between the two scores ( $\mathrm{r}$ $=-0.6066)$. This result is in agreement with Lee et al. [11] who found a significant negative correlation of $\mathrm{r}=-0.4$ between the two scores among the AD patients group.

Although increased score of $\mathrm{MNi}$ can be associated with different disease conditions and cannot be considered specific for AD [27]; however, the significant correlation between the scores of MNi and MMSE among the patients in our study can augment the prospect of using the $\mathrm{MNi}$ as a biomarker for the risk of cognitive decline and for early diagnosis of AD [11].

Zhang et al. [31] declared that increase frequency of $\mathrm{MNi}$ formation is associated with increased occurrence of chromothripsis. Chromothripsis occurs when a chromosome or a part of a chromosome experiences enormous shattering and consequent reunion of a single chromatid from a micronucleus which can result in accumulated affection of the DNA constitutes within the cells. This can result in a massive acquired genomic rearrangement in a single devastating event [32]. Consequently, this loss of genome integrity may be associated with increased risk for neurodegenerative disease [11]. So, we postulate that this mechanism may underlie the progressive course of $\mathrm{AD}$ and consecutive evaluation of the score of MNi for AD patient may help in follow-up. Continued research on micronucleated cells can unravel further unknown pathogenesis of different diseases including cancer and neurodegenerative diseases [33].

By comparing the association between cognitive state and both MNi scoring $(\mathrm{r}=-0.6066)$ and the absolute power of alpha wave $(r=0.2235)$ among the patients, we found that the $\mathrm{MNi}$ scoring is more correlated to the cognitive state which can reflect the distressing effect of genetic damage. This difference between the two correlations may be attributed to the early occurrence of genomic instability than the EEG changes, so at certain level of cognitive impairment genomic instability could be more obvious than the EEG changes. Also, the association between the cognitive state and the EEG changes may become more apparent with increasing the sample size, so subsequent studies with a larger number of $\mathrm{AD}$ patients are recommended.

The non-significant correlation between the value of alpha wave power and the MNi scoring among the patients group in our study $(\mathrm{r}=-0.06844)$ could also be rationalized by the difference in the course of the two parameters as the genomic instability is suggested to precede the EEG changes.

\section{Conclusions}

In the current study, we hypothesize that using combined markers including both cytogenetic and neurophysiological markers can augment the possibility of preclinical and early diagnosis of $\mathrm{AD}$. The correlation between the scores of MMSE and MNi among the patients in our study is suggestive for the impact of genomic instability on the cognitive state of $\mathrm{AD}$ patients. Although cytogenetic and neurophysiological markers are defective in reaching a definitive diagnosis, they can increase the diagnostic sensitivity and specificity.

\section{Abbreviations}

AD: Alzheimer's disease; BN: Binucleated cells; DNA: Deoxyribonucleic acid; EEG: Electroencephalogram; MMSE: Mini-Mental State Examination; MNi: Micronuclei; MRI: Magnetic resonance imaging

\section{Acknowledgements}

The authors acknowledge the patients and the controls for participating in this study. 


\section{Authors' contributions}

D.H. performed the cytogentic study, wrote the manuscript and statistical analysis of the data. A.F. and M.M. performed the clinical examination and neurophysiological studies. S.H. supervised the study and shared in writing the manuscript. The authors read and approved the final manuscript.

\section{Funding}

The research study is self-funded.

\section{Availability of data and materials}

The datasets generated during and/or analyzed during the current study are available from the corresponding author on reasonable request.

\section{Declarations}

\section{Ethics approval and consent to participate}

The study was conducted according to the guidelines of the Medical Research Ethics Committee of the National Research Centre based on the World Medical Association Declaration of Helsinki, and written informed consents have been taken from the patients or their guardians as well as from controls.

The informed consents obtained were written consents.

We have not got a reference number, the whole work including sample withdrawal and the written informed consents have been performed according to the guidelines of the Medical Research Ethics Committee of the National Research Centre.

\section{Consent for publication}

Not applicable.

\section{Competing interests}

The authors have no conflicts of interest to declare.

\section{Author details}

'Department of Human Cytogenetics, Human Genetics and Genome Research Division, The National Research Centre, 33 El Buhouth Street, El-Dokki, Cairo 12622, Egypt. ${ }^{2}$ Department of Neurophysiology, Faculty of Medicine, Cairo University, Cairo, Egypt. ${ }^{3}$ Department of Neurology, Faculty of Medicine, Al-Azhar University, Cairo, Egypt.

Received: 8 July 2020 Accepted: 9 June 2021

Published online: 01 July 2021

\section{References}

1. Pond D (2012) Dementia an update on management. Aust Fam Phys. 41(12):936-939

2. Steel J, Eslick D (2015) Herpes viruses increase the risk of Alzheimer's disease: a meta-analysis. J Alzheimer's Dis. 47(2):351-364. https://doi.org/1 0.3233/JAD-140822

3. Barnes DE, Yaffe K (2011) The projected effect of risk factor reduction on Alzheimer's disease prevalence. Lancet Neurol 10:819-828

4. Alzheimer's Disease Facts and Figures. Alzheimer's dement. 2020 ; 16:391-460

5. Villemagne VL, Burnham S, Bourgeat P, Brown B, Ellis KA, Salvado O, Szoeke C, Macaulay SL, Martins R, Maruff P, Ames D, Rowe CC, Masters CL (2013) Amyloid $\beta$ deposition, neurodegeneration, and cognitive decline in sporadic Alzheimer's disease: a prospective cohort study. Lancet Neurol. 12(4):357-367. https://doi.org/10.1016/S1474-4422(13)70044-9

6. ZHOU X, JIA J (2010) P53-mediated G1/S checkpoint dysfunction in lymphocytes from Alzheimer's disease patients. Neurosci. Lett. 468(3):320325. https://doi.org/10.1016/.neulet.2009.11.024

7. Zivković L, Spremo-Potparević B, Siedlak SL, Perry G, Plećaš-Solarović B, Milićević Z, Bajić VP. .DNA damage in Alzheimer disease lymphocytes and its relation to premature centromere division. Neurodegener Dis. 2013; 12: 156-163, 3, doi: https://doi.org/10.1159/000346114.

8. Bajic V, Bajic VB, Zivkovic L, Arendt T, Perry G, Spremo-Potparevic B (2016) Late phase cell cycle proteins in Alzheimer's disease: a possible target for therapy? J Syst Integr Neurosc. 3:1-8

9. Fenech M, Kirsch-Volders M, Natarajan AT, Surralles J, Crott JW, Parry J, Norppa H, Eastmond DA, Tucker JD, Thomas P (2011) Molecular mechanisms of micronucleus, nucleoplasmic bridge and nuclear bud formation in mammalian and human cells. Mutagenesis 26(1):125-132. https://doi.org/10.1093/mutage/geg052

10. Migliore L, Coppede F, Fenech M, Thomas P (2011) Association of micronucleus frequency with neurodegenerative diseases. Mutagenesis. 26(1):85-92. https://doi.org/10.1093/mutage/geq067

11. Lee SL, Thomas P, Hecker J, Faunt J, Fenech M (2015) Chromosomal DNA damage measured using the cytokinesis-block micronucleus cytome assay is significantly associated with cognitive impairment in South Australians. Environ Mol Mutagen. 56(1):32-40. https://doi.org/10.1002/em.21890

12. Cedazo-Minguez A, Winblad B (2010) Biomarkers for Alzheimer's disease and other forms of dementia: clinical needs, limitations and future aspects. Exp Gerontol 45(1):5-14. https://doi.org/10.1016/j.exger.2009.09.008

13. Snyder SM, Hall JR, Cornwell SL, Falk JD (2011) Addition of EEG improves accuracy of a logistic model that uses neuropsychological and cardiovascular factors to identify dementia and MCl. Psychiatry Res. 186(1): 97-102. https://doi.org/10.1016/j.psychres.2010.04.058

14. Smailovic U, Jelic V (2019) Neurophysiological markers of Alzheimer's disease: quantitative EEG approach. Neurol Ther. 8(S2):37-55. https://doi. org/10.1007/s40120-019-00169-0

15. American Psychiatric Association. Diagnostic and statistical manual of mental disorders DSM-5 ${ }^{\oplus}$. Arlington: American Psychiatric Pub; 2013.

16. Folstein M, Folstein S, McHugh P (1975) "Mini-mental state". A practical method for grading the cognitive state of patients for the clinician. J Psychiatr Res. 12(3):189-198. https://doi.org/10.1016/0022-3956(75)90026-6

17. El OkI MA. Prevalence of Alzheimer dementia and other causes of dementia in Egyptian elderly. Cairo: MD, Faculty of medicine, Ain Shams University 2002.

18. Fenech M, Chang WP, Kirsch-Volders M, Holland N, Bonassi S, Zeiger E, HUman MicronNucleus project (2003) HUMN project: detailed description of the scoring criteria for the cytokinesis-block micronucleus assay using isolated human lymphocyte cultures. Mutat Res. 534(1-2):65-75. https://doi. org/10.1016/S1383-5718(02)00249-8

19. Sharma N, Singh AN (2016) Exploring biomarkers for Alzheimer's disease. JCDR. 10:KE01-KKE6

20. Al-Qazzaz NK, Ali SHB, Ahmad SA, Chellappan K, Islam MS, Escudero J (2014) Role of EEG as biomarker in the early detection and classification of dementia. Sci. World J 2014:Article ID 906038

21. Henderson G, Ifeachor E, Hudson N, Goh C, Outram N, Wimalaratna S, del Percio C, Vecchio F (2006) Development and assessment of methods for detecting dementia using the human electroencephalogram. IEEE Transact Biomed Eng. 53(8):1557-1568. https://doi.org/10.1109/TBME.2006.878067

22. Tsolaki A, Kazis D, Kompatsiaris I, Kosmidou V, Tsolaki M. Electroencephalogram and Alzheimer's disease: clinical and research approaches. Int J Alzheimers Dis. 2014:349249.

23. De Waal H, Stam CJ, Blankenstein M (2011) YaL Pijnenburg, Scheltens P, van der Flier WM. EEG abnormalities in early and late onset Alzheimer's disease: understanding heterogeneity. J Neurol Neurosurg Psychiatry. 82(1):67-71. https://doi.org/10.1136/jnnp.2010.216432

24. Fauzan N, Amran NH (2015) Early detection of mild cognitive impairment, dementia and Alzheimer's using Qeeg. Eur J Interdisc Stud. 1:152-159

25. Micanovic C, Pal S (2014) The diagnostic utility of EEG in early-onset dementia: a systematic review of the literature with narrative analysis. Journal of neural transmission. J Neural Transm. 121(1):59-69. https://doi. org/10.1007/s00702-013-1070-5

26. Raymundo C, Mar E, Rodrigo SM, Francisco F, Tiago F (2018) Systematic review on resting-state EEG for Alzheimer's disease diagnosis and progression assessment. Dis Markers. https://doi.org/10.1155/2018/5174815

27. Andreassi MG, Barale R, lozzo P, Picano E (2011) The association of micronucleus frequency with obesity, diabetes and cardiovascular disease. Mutagenesis. 26(1):77-83. https://doi.org/10.1093/mutage/geq077

28. Trippi F, Botto N, Scarpato R, Petrozzi L, Bonuccelli U, Latorraca S, Sorbi S, Migliore L (2001) Spontaneous and induced chromosome damage in somatic cells of sporadic and familial Alzheimer's disease patients. Mutagenesis. 16(4):323-327. https://doi.org/10.1093/mutage/16.4.323

29. Petrozzi L, Lucetti C, Scarpato R, Gambaccini G, Trippi F, Bernardini S, Del Dotto P, Migliore L, Bonuccelli U (2002) Cytogenetic alterations in lymphocytes of Alzheimer's disease and Parkinson's disease patients. Neurol Sci. 23(0):S97-S98. https://doi.org/10.1007/ s100720200087

30. Fenech M, Bonassi S (2011) The effect of age, gender, diet and lifestyle on DNA damage measured using micronucleus frequency in human peripheral 
blood lymphocytes. Mutagenesis 26(1):43-49. https://doi.org/10.1093/muta ge/geq050

31. Zhang CZ, Spektor A, Cornils H, Francis JM, Jackson EK, Liu S, Meyerson M, Pellman D (2015) Chromothripsis from DNA damage in micronuclei. Nature. 522(7555):179-184. https://doi.org/10.1038/nature14493

32. Luijten MNH, Lee JXT, Chen S, Crasta KC 2018. Generation of micronuclei and detection of chromosome pulverization. In: Pellestor F, editors. Chromothripsis. Methods in Molecular Biology. Humana Press, New York. vol. 1769; p. 183-197.

33. Soto M, García-Santisteban I, Krenning L, Medema RH, Raaijmakers JA (2018) Chromosomes trapped in micronuclei are liable to segregation errors. J Cell Sci 131:jcs214742

\section{Publisher's Note}

Springer Nature remains neutral with regard to jurisdictional claims in published maps and institutional affiliations.

\section{Submit your manuscript to a SpringerOpen ${ }^{\circ}$ journal and benefit from:}

- Convenient online submission

- Rigorous peer review

- Open access: articles freely available online

- High visibility within the field

- Retaining the copyright to your article

Submit your next manuscript at $\boldsymbol{\nabla}$ springeropen.com 